\title{
A Preliminary Study on Energy Saving Smart Space Using Location Awareness Technology
}

\author{
Ki-Hyun Choi, Heangwoo Lee and Yongseong Kim \\ Graduate School of Techno Design, Kookmin University, \\ Seongbuk-gu, Seoul, 136-702, Republic of Korea \\ Meta_ku@naver.com,moonup2001@nate.com,yongkim@kookmin.ac.kr
}

\begin{abstract}
As the issue of conserving energy is a major current global issue, concerns and efforts from all circles are required. With such a background, technology realizing Smart Space utilizing IT technology is recently drawing attention as an effective method of reducing building energy consumption. This study investigates Smart Control System to collect the fundamental materials necessary to realize Smart Space and suggests Smart Lighting Control System, with better efficiency and performance than the existing lighting control system. The suggested model proves its effectiveness in a test bed. After a performance evaluation of the proposed model, the energy saving effect of 22 47\% compared to the existing lighting control system could be confirmed. In future studies, I believe that research in the saving of lighting energy during the night should follow to propose a more sophisticated smart lighting control system.
\end{abstract}

Keywords: Smart Space, Smart Lighting Control System, Energy Saving

\section{Introduction}

As the issue of conserving energy is a major current global issue, concerns and efforts from all circles are required. Among them, the issue of the continued increase in the usage of energy in buildings is considered as one of the worst examples of serious energy waste, and an area where countermeasures are urgently needed. With such a background, technology realizing Smart Space utilizing IT technology is recently drawing attention as an effective method of reducing building energy consumption. It provides for the efficient management of energy consumption and a comfortable, user-oriented indoor environment through Smart Control System that utilizes the range of space information available these days. This study investigates Smart Control System to collect the fundamental materials necessary to realize Smart Space and suggests Smart Lighting Control System, with better efficiency and performance than the existing lighting control system. The suggested model proves its effectiveness in a test bed.

\section{Investigation into a Smart Space}

\subsection{Smart Control System}

Smart Control System comes into action with the linkage of three processes. In the first process, it effectively senses the necessary information in the countless pieces of environmental information occurring in any indoor space. In the second process, it analyzes 
the gathered environment information for the purpose of managing the system. It has differentiated intelligent characteristics throughout this process. In the third process, it responds to the content it has analyzed and directly controls the environment. With these processes, the indoor environment can be maintained at optimized conditions at all time. To maintain the performance of Smart Control System, all three processes should be automatized and respond to the environment in real-time.

\subsection{Smart Space Utilizing User Position Awareness Technology}

Smart Space utilizing user position awareness technology provides an optimal environment to the user through the intelligent and active control of the air conditioning, lighting and ventilation systems after analyzing the environmental information of the space in which the user is located. The process of user position awareness applies in the order of the three stages of the confirmation of whether or not there is a user in the whole space, whether or not there is a user in each room, and detailed spatial location. First, it determines the information to be identified when a user enters a space. It confirms the registered information upon the user's entrance to the space and begins tracing the user's specific location. On the other hand, if the user departs from the space, the system senses that, and saves energy by disconnecting the lighting, air conditioning and ventilation. Second, it determines the user's specific location within the whole space. The environment control system comes into action in accordance with the user's location in each space. It saves energy by disconnecting the lighting, air conditioning and ventilation service in any area in which no user is considered to be located. Third, it infers the activity state of users, such as dining, reading, or sleeping from touches shown in specific furniture pieces, home appliances and the location of the user. It realizes maximized comfort and energy savings by adjusting the level of the service quality of lighting, air conditioning, and ventilation according to these pre-determined conditions.

\section{Smart Lighting Control System}

\subsection{Proposal of a Basic Model of a Smart Lighting Control System Technology}

Table 1. Investigation into a Sensor-based Dimming System

\begin{tabular}{|c|c|c|}
\hline & Control Method & Contents \\
\hline $\begin{array}{l}\text { Sensor- } \\
\text { based } \\
\text { Dimming } \\
\text { System }\end{array}$ & $\begin{array}{l}\text { controls luminance through } \\
\text { dimming after sensing whether } \\
\text { there is a user in the room } \\
\text { and luminance brought in from } \\
\text { outside }\end{array}$ & $\begin{array}{l}\text { - Linked system between sensor technology and } \\
\text { dimming } \\
\text { - Combined method of manual and automatic controls } \\
\text { - Various applications are available depending on the } \\
\text { Algorithm construction method. }\end{array}$ \\
\hline
\end{tabular}

The sensor-based dimming system has overcome the shortcomings of the on/off method and secured a certain amount of energy efficiency. However, as the scope of information detection is limited to motion sensing and luminance brought in from outside, there is a limitation in that it is difficult to cope with detailed situations, and especially the saving effect of lighting energy during the night is very low. Thus, in order to efficiently cope with power consumption, the scope of information detection of sensors should be widened and the capacity to effectively cope with more situations is required. As the consumption of artificial lighting is especially concentrated during the night, it is necessary that a model to reduce energy consumption during the night is proposed. 


\subsection{Scenario of a Smart Lighting Control System}

The system, first of all, determines the presence of any user in the space through a motion detecting sensor and controls, by an on/off method, the overall luminance. After any motion of the user is detected, it locates the specific position within the space, and the current luminance is measured centering on the located position. If the measured luminance value does not reach 400lux, the living standard luminance, any shortage of luminance is additionally provided through dimming, and if it exceeds 400lux, it is reduced to the appropriate level.

\section{Performance Evaluation}

\subsection{Setting of the Experiment and Method of Performance Evaluation}

The method of the experiment was as follows: The physical space of the test bed is divided into four areas in order to set up user location awareness. The LED dimming system is installed on the center of the ceiling of each divided area. By installing the luminance sensor to match the position of lighting on the ceiling, the measurement of phased luminance according to the dimming system shall be made available. At this time, luminance sensors shall be installed by assuming that the average work plane is $800 \mathrm{~mm}$ above the floor. The set time to derive experimental values is between 12:00-1:00 p.m., when the solar altitude is highest with a full south direction, in accordance with the conditions of the test bed. The required luminance of the user is set at 400lux on the basis of the KS luminance standard.

\section{Table 2. Results of the Measurement of Luminance Brought into the Indoors at Noon from Full South}

\begin{tabular}{c|c|c|c|c}
\hline & ZONE_1 & ZONE_2 & ZONE_3 & ZONE_4 \\
\hline Summer Solstice & 329.92 & 1310.41 & 389.85 & 2599.82 \\
\hline Spring and Autumnal Equinoxes & 472.74 & 1325.28 & 577.89 & 2736.34 \\
\hline Summer Solstice & 910.33 & 1787.03 & 1351.19 & 13433.27 \\
\hline
\end{tabular}

The results of measuring the luminance brought into the indoors by seasons according to the given setup is as shown in Table 2. As the luminance on the spring and autumnal equinoxes and winter solstice, according to the measurement of the luminance by season around noon with a full south direction, exceeds 400lux, the required luminance under the actual living environment, it is excluded from the experiment condition by setting up such hours in which artificial lighting is not used. The experiment was conducted by assuming that the occupant in the space is one person with a setup in which four divided areas are sequentially used.

Table 3. Three Types of Experiments

\begin{tabular}{c|c|c}
\hline & Location Awareness & Lighting Control \\
\hline TYPE_1 & None & On/Off [Lv8] \\
\hline TYPE_2 & Apply & On/Off [Lv8] \\
\hline TYPE_3 & Apply & Dimming [Lv1 Lv8] \\
\hline
\end{tabular}


The total of three types of lighting control systems are comparatively analyzed in order to derive the final performance evaluation results according to the experiment. Three types of lighting control systems are, firstly, the on/off type that does not apply location awareness; secondly, the on/off type that applies location awareness; and thirdly, the dimming type that applies location awareness. The energy saving effects are finally verified after a comparative analysis of the power consumption of each system.

\subsection{Results of the Experiment}

Table 4. Collection of Data by Experiment

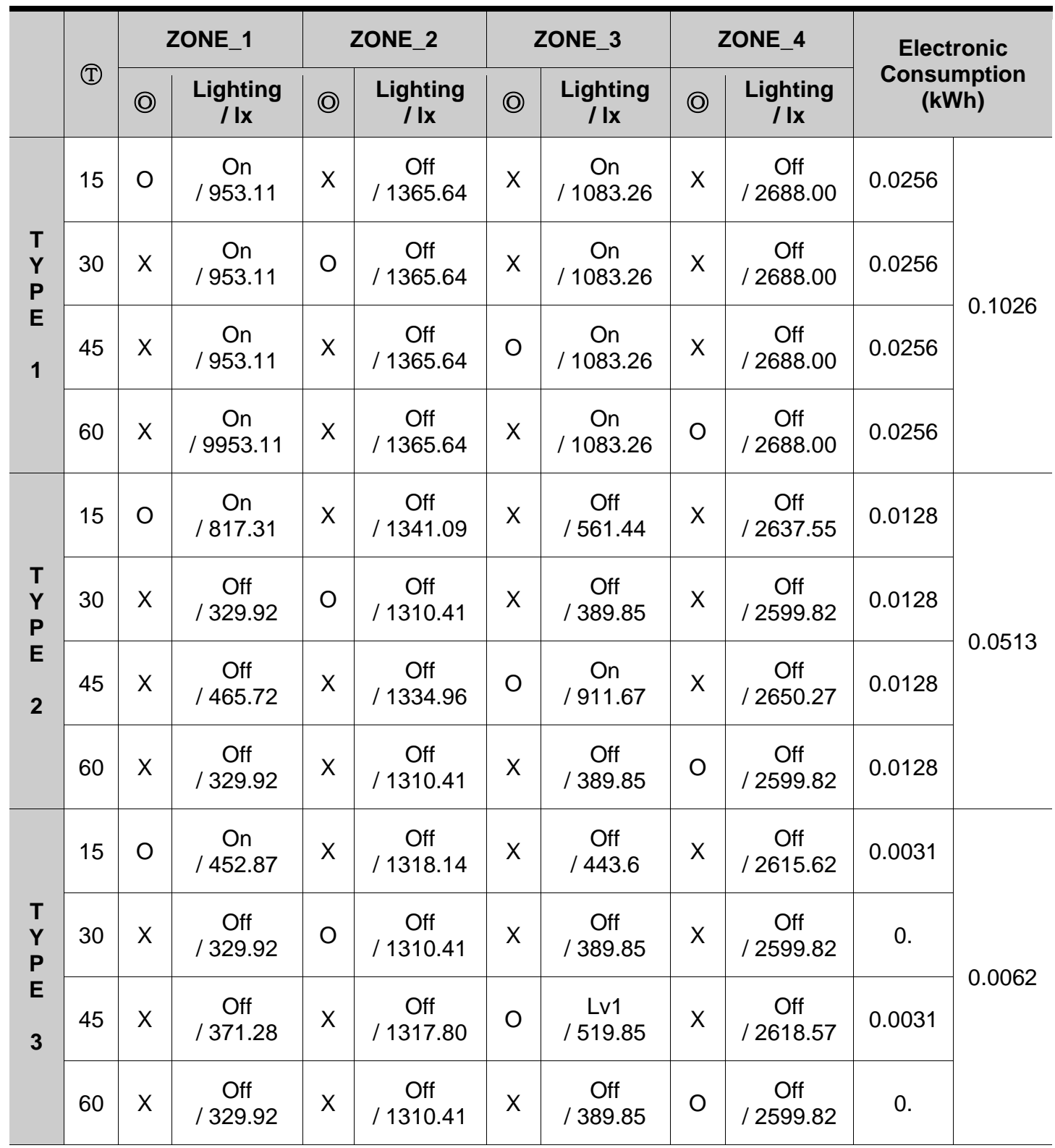

(T) : Time (m) (O) : Occupant's Location 


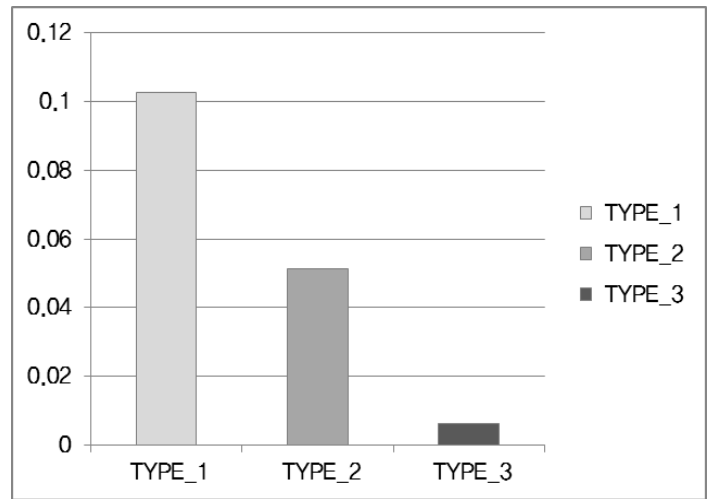

\section{Figure 1. Comparative Analysis of Power Consumption of the Lighting Control System}

The results from the experiment of this study is as follows: It was shown that the respective energy saving rates are $50 \%$ for the on/off system, $75 \%$ for the sensor-based dimming system, and $97 \%$ for the smart lighting control system that applies location awareness technology. The system that showed the highest energy saving effect is the smart lighting control system that applies location awareness technology.

\section{Conclusion}

In this study, I suggested Smart Lighting Control System as a means to collect the basic material of Smart Space and conducted the experiment for performance testing in a test bed. The main results of this study can be summarized as follows: First, a smart lighting control system can realize maximized energy savings by collecting information through sensors and actively and reasonably responding to various situations. The main process of the smart system is performed by repeating the process of detection of information and analysis thereof through an algorithm, and presenting a proper response. Second, in order to improve the energy saving effect of a smart lighting control system, the scope of information collected through sensors should be expanded from being environment-oriented to user-oriented. Thus, this study proposes a basic model of a smart lighting control system that applies location awareness technology. Third, I can verify a $22 \sim 47 \%$ energy saving rate of the smart lighting control system that applies the location awareness technology as proposed in this study.

\section{References}

[1] H. -W. Lee, H. -D. Jeong and Y. -S. Kim, "A Basic Study on Application of User and Location Awareness for the Green Home IT", Journal of Architectural Institute of Korea, vol. 28, no. 1, (2012).

[2] S.-O. Cho, "A Study on the Development of Building Control and management System: Focusing on the Lighting Control and Monitoring system", Journal of Korean Institute of Interior Design, vol. 16, no. 4, (2007).

[3] H. -M. Lee and H. -S. Kim, “An Experimental Study on the Lighting Control System for Appling for Home Network", The Society of Living Environment system, Korea, vol. 16, no. 5, (2009).

[4] A. -S. Choi, J. -E. Lee and B. -C. Park, "Development and Application of Health Lighting Plan in Residential Areas", Journal of Architectural Institute of Korea, vol. 20, no. 10, (2004).

[5] A. -S. Choi and J. -E. Lee, "A Study of Luminous Environment for Standard Illuminance in Residential Areas", Journal of Korean Institute of Illuminating and Electrical Installation Engineers, vol. 19, no. 3, (2005).

[6] S. P. Han, "A Study on Lighting Control Method for Harmonization of Daylighting and Artificial Lighting Development of Visual Model for Harmony and Comfort in Interior Space", Journal of Architectural Institute of Korea, vol. 26, no. 8, (2010). 
[7] S. -R. Ryu, K. -N. Lee, M. -S. Yeo and K. -W Kim, "A Study on the Home Network Systems for the Integrated Control of the Indoor Environment", Journal of Architectural Institute of Korea, vol. 25, no. 1, (2005).

[8] C. Soo, "The Technical Development Status of Energy Convergence Building”, Journal of Architectural Institute of Korea, vol. 53, no. 2, (2009).

[9] Samoo Architects \& Engineers, Editor, NET ZERO: Sustainable Design Process of Zero Energy House, Korea, (2010).

[10] C. K. Hyun, H. Lee and Y. Kim, "Proposal of a Basic Model of Smart Lighting Control Applying Location Awareness Technology", Workshop on Architecture and Civil Engineering Second, (2013). 